\title{
BLOODY NIPPLE DISCHARGE IN INFANCY
}

\author{
Ivana UNIC SABASOV ${ }^{1}$, Veselin SKRABIĆ ${ }^{1}$, Vedrana BULJEVIĆ ${ }^{2}$
}

\author{
${ }^{1}$ Clinical Hospital Split \\ Department of Pediatrics \\ Split, Croatia, ${ }^{2}$ Private Clinical Practice \\ for Breast Diseases, Split, Croatia \\ Corresponding author: \\ Ivana Unic Sabasov \\ Clinical Hospital Split \\ Department of Pediatrics \\ Spinciceva 1 \\ 21000 Split \\ Croatia \\ iunic@kbsplit.hr \\ Tel.: + 38521556287 \\ Fax.: + 38521556590
}

Received: February 15, 2013

Accepted: June 10, 2013

Copyright (C) 2013 by University Clinical Center Tuzla. E-mail for permission to publish: paediatricstoday@ukctuzla.ba

\begin{abstract}
Objective - We present three infants with bloody nipple discharge (BND). This rare clinical entity is mostly related to benign conditions such as ductal ectasia and epithelial hyperplasia. However, BND may be the first symptom of breast carcinoma and for this reason, it causes anxiety in parents. Case reports - The infants were older than six-months with unilateral left-sided BND and had normal physical exams. Haematological and endocrinological test results were within normal limits in all but one infant, who had increased follicle stimulating hormone and prolactin. Ultrasonography of the breasts showed asymmetry in the quantity of mammary tissue and the discrete dilated ducts. Cytologic examination of the BND did not reveal any inflammatory signs or atypical cells. The BND resolved spontaneously within six months without any specific treatment. Conclusion - Our findings confirm previously reported observations that BND in infants is associated with ductal ectasia and epithelial hyperplasia. This condition is benign and disappears spontaneously so no specific management intervention is needed.
\end{abstract}

Key words: Bloody nipple discharge - Infant - Mammary duct ectasia - Hyperplasia - Management.

\section{Introduction}

Infantile bloody nipple discharge (BND) is a rare clinical entity mostly related to benign conditions such as ductal ectasia and epithelial hyperplasia (1-3). Parents may be anxious if they believe BND to be the first symptom of breast carcinoma. We report three cases of unilateral infantile BND associated with both ductal ectasia and epithelial hyperplasia, including management recommendations.

\section{Case reports}

The first case was an 11-month-old male infant. The second case was a nine-month-old female infant. Both infants presented with a unilateral bloody discharge from the left nipple that appeared 20 and 45 days before the first examination, respectively. The third case was a six-month-old male infant with bloody discharge from the left nipple which appeared a few days before the first examination. The deliveries were uneventful, the infants were breastfed and their mothers were not taking any medication. At the time of presentation, all breasts were normal in colour and without palpable masses. On light pressure, a bloody discharge appeared from only the left nipple in all infants. Hematological and endocrinological test results were within normal limits. In only the third infant, the follicle 
stimulating hormone (FSH) was increased on two separate occasions (15 and $14.7 \mathrm{IU} / \mathrm{l}$, referent value $\leq 2.5 \mathrm{IU} / \mathrm{l})$ as well as prolactin (601 IU/l and $593 \mathrm{IU} / \mathrm{l}$, referent value $<324$ IU/l). Ultrasonography of the breasts showed asymmetry in the quantity of mammary tissue, where it was much more pronounced in the terminal duct lobular unit and with the discrete dilatated ducts in the left breast. Cytologic examination of the BND did not reveal any inflammatory signs or atypical cells. The BND resolved spontaneously in the first and second infant after approximately two and three weeks, respectively. In the third case, the BND disappeared after six months. The infants were free of recurrence during 24-months of follow-up.

\section{Discussion}

Fifty years ago, Myers and Kaplan (2) first reported BND in a four-month-old female infant. This entity is quite rare but the number of published studies regarding this condition has increased lately for at least two reasons (1). First, the cause of infantile BND is unclear. Second, treatment approaches are not well defined. We came upon the same observations as previously published, since our cases were older than six-months, with unilateral spontaneous left-sided BND and normal physical exam. A variety of benign and malignant ductal conditions may cause infantile BND, including mammary epithelial hyperplasia and ductal ectasia. Mammary epithelial hyperplasia is characterized by an increase in the number of cells lining the ducts. Ductal ectasia is characterized by dilatation of the major ducts, usually in the subareolar region and associated with various degrees of inflammatory reaction (3-5). Other etiologic factors may be congenital abnormalities of the ductal system, autoimmune reactions, and extramedullary hematopoiesis and hemophagocytosis $(6,7)$. McKi- ernan et al. $(8,9)$ show that the human mammary gland continues to be active for several months after birth and may continue to grow and secrete. It seems also that breast development continues until four years of age, with a well-formed lobular pattern and secretory function.

In general, estrogen promotes growth of the ductal system, and progesterone that of the alveoli. Plasma estradiol concentrations are often higher in girls aged 0-4 years than in later prepubertal years. Circulatory concentrations of FSH rise after birth in both sexes and in girls remain relatively high for the next few years. Maternal hormones, including estrogen, progesteron and prolactin, appear to influence the hypertrophy of neonatal breast tissue. We found that our infants had normal hematological and endocrinological test result in all but one case, who had increased FSH and prolactin.

The BND in our cases was probably an effect of hormonal influence in the infants themselves on the neonatal breasts and a mechanism causing bloody discharge from intraductal papillomas. Moreover, it is suggested that BND might be a normal finding during the first months of life (10). The cytological findings in our patients were the basis for a wait and see attitude. The BND in these cases diminished up to six months after presentation. This observation was in accordance with the published findings (1). The infants were followed-up for 24 months, and no recurrence occurred. We suggest that similar cases of infantile BND should be managed expectantly, with repeated clinical assessments. We used ultrasonography in follow-up of the patients.

Our ultrasonography findings are similar to those reported in the literature and this diagnostic tool seems to be a valuable noninvasive method for follow-up of BND (1). To our knowledge, no case of breast cancer in the first year of life has yet been reported. 
Most malignant breast masses result from metastasis of other malignant neoplasms, such as Hodgkin's and non Hodgkin's lymphomas, rhabdomyosarcoma, hepatocarcinoma and neuroblastomas (4, 11-17). Regarding the small risk of malignant breast disease in infants, breast biopsy or excision should be avoided. However, biopsy or excision may be considered in the case of longer persistence of discharge, the presence of atypical cells, or dubious ultrasonographic findings $(1,17-18)$.

\section{Conclusion}

Bloody nipple discharge in infants is mostly a benign condition associated with ductal ectasia and epithelial hyperplasia. This condition resolves spontaneously so similar cases may be managed expectantly and no specific management intervention is needed.

Authors' contributions: Conception and design: IUS and VS; Acquisition, analysis and interpretation of data: IUS, VS, and VB; Drafting the manuscript: IUS and VS; Revising it critically for important intellectual content: IUS and VS.

Conflict of interest: The authors declare that they have no conflict of interest.

\section{References}

1. Pleša Premilovac Z, Tokić V. Bloody nipple discharge in infancy: a case report and recommendations for management. J Pediatr Adolesc Gynecol. 2013;26:16-8.

2. Myers MB, Kaplan IW. Bleeding from the nipple in infancy due to cystic ductal hyperplasia of the breast. Ann Surg. 1956;143:557-60.

3. Stringel G, Perelman A, Jimenez C. Infantile mammary duct ectasia: a cause of bloody nipple discharge. J Pediatr Surg. 1986;21:671-4.

4. West KW, Rescorla FJ, Scherer LR 3rd, Grosfeld JL. Diagnosis and treatment of symptomatic breast masses in the pediatric population. J Pediatr Surg. 1995;30:182-7.
5. Berkowitz CD, Inkelis SH. Bloody nipple discharge in infancy. J Pediatr. 1983;103:755-6.

6. Böber E, Ozer E, Akgür F, Büyükgebiz A. Bilateral breast masses and bloody nipple discharge in a two year-old boy. J Pediatr Endocrinol Metab. 1996;9:419-21.

7. Pampal A, Gokoz A, Sipahi T, Dogan H, Ergur AT. Bloody nipple discharge in 2 infants with interesting cytologic findings of extramedullary hematopoiesis and hemophagocytosis. J Pediatr Hematol Oncol. 2012;34:229-31.

8. McKiernan JF, Hull D. Breast development in the newborn. Arch Dis Child. 1981;56:525-9.

9. McKiernan J, Coyne J, Cahalane S. Histology of breast development in early life. Arch Dis Child. 1988;63:136-9.

10. Tan R, Van Bosstraeten B, Casteels K. Does bloody nipple discharge occur during normal breast development in infancy? Pediatr Int. 2010;52:825-7.

11. Stricker T, Navratil F, Sennhauser FH. Mastitis in early infancy. Acta Paediatr. 2005;94:166-9.

12. Weinstein SP, Conant EF, Orel SG, Zuckerman JA, Bellah R. Spectrum of US findings in pediatric and adolescent patients with palpable breast masses. Radiographics. 2000;20:1613-21.

13. Chateil JF, Arboucalot F, Perél Y, Brun M, BoisserieLacroix M, Diard F. Breast metastases in adolescent girls: US findings. Pediatr Radiol. 1998;28:832-5.

14. Rogers DA, Lobe TE, Rao BN, Fleming ID, Schropp KP, Pratt AS, et al. Breast malignancy in children. J Pediatr Surg. 1994;29:48-51.

15. Kapila K, Pathan SK, Al-Mosawy FA, George SS, Haji BE, Al-Ayadhy B. Fine needle aspiration cytology of breast masses in children and adolescents: experience with 1404 aspirates. Acta Cytol. 2008;52:681-6.

16. Karl SR, Ballantine TV, Zaino R. Juvenile secretory carcinoma of the breast. J Pediatr Surg. 1985;20:368-71.

17. Imamoglu M, Cay A, Reis A, Ozdemir O, Sapan L, Sarihan H. Bloody nipple discharge in children: possible etiologies and selection of appropriate therapy. Pediatr Surg Int. 2006;22:158-63.

18. Weimann E. Clinical management of nipple discharge in neonates and children. J Paediatr Child Health. 2003;39:155-6. 